\title{
Metodologia de Pesquisa das Crenças sobre Aprendizagem de Línguas: Estado da Arte ${ }^{1}$
}

\author{
Ana Maria Ferreira Barcelos \\ Universidade Federal de Viçosa
}

Language learning beliefs have been a topic in Applied Linguistics for 15 years now. Beliefs are considered as one of the individual learning differences that may influence the learning/acquisition process. Many studies have been published about language learning beliefs but few of them have examined the methodology of investigating beliefs. This paper is a state-ofart review of current research methodology on students" language learning beliefs. The author groups studies on language learning beliefs into three approaches according to their definition of beliefs, methodology, and the relationship between beliefs and actions. The main advantages and disadvantages of each approach are discussed and questions for the future research on students' language learning beliefs are offered at the end.

\section{Introdução}

O interesse pelo tópico de crenças sobre aprendizagem de línguas em Lingüística Aplicada (doravante LA) surgiu em meados dos anos 80. Se comparado com outras áreas como Sociologia, Antropologia, Psicologia e Educação esse interesse é bastante recente, embora venha crescendo significativamente nos últimos anos. A edição especial do periódico System a respeito de crenças sobre aprendizagem de línguas e um simpósio sobre crenças, realizado na conferência da AILA em Tóquio, em 1999, sugerem o crescente interesse por esse tópico em LA. Embora existam vários estudos sobre crenças, nenhum deles (com exceção de Kalaja, 1995) se preocupou, até o momento, em fazer uma revisão dos tipos de metodologias utilizadas na investigação das crenças sobre aprendizagem de línguas.

Neste trabalho, argumento que, até agora, a pesquisa a respeito de crenças sobre aprendizagem de línguas tem feito apenas uma descri-

\footnotetext{
${ }^{1}$ Uma versão anterior desse trabalho foi apresentada no $12 \mathrm{th}$ World Congress of Applied Linguistics, em Tóquio, Japão, Agosto 1-6, 1999.
} 
ção dessas crenças, mas não tem tentado entender porque os alunos possuem certas crenças, a sua origem e o papel que algumas delas exercem no processo de aquisição de línguas. Inicialmente, faço uma breve revisão do conceito de crenças e da relação entre crenças e ação. ${ }^{2}$ Em seguida, faço uma revisão da metodologia dos estudos sobre crenças, a respeito de aprendizagem de línguas, agrupando-os em três abordagens de acordo com sua definição de crenças, métodos de investigação e relação entre crenças e ação, discutindo as vantagens e desvantagens de cada abordagem. Concluo o artigo com perguntas e sugestões que podem constituir tópicos de investigações futuras.

\section{Crenças e ações}

Pajares (1992) afirma que as crenças são um conceito complexo. Parte dessa complexidade deve-se à existência de diferentes termos usados para se referir às crenças. Esse fenômeno também acontece em LA, onde se encontram termos como "representações dos aprendizes" (Holec, 1987), "filosofia de aprendizagem de línguas" (Abraham \& Vann, 1987), "conhecimento metacognitivo" (Wenden, 1986), e "cultura de aprender línguas" (Almeida Filho, 1993; Barcelos, 1995), referentes às crenças. Essa profusão de termos, apesar de ser prejudicial, indica o potencial deste conceito para a LA. A importância das crenças sobre aprendizagem tem sido relacionada principalmente com sua influência na abordagem de aprender dos alunos e no ensino autônomo.

Apesar de ainda não haver uma definição uniforme a respeito de crenças sobre aprendizagem de línguas, em termos gerais, elas podem ser definidas como opiniões e idéias que alunos (e professores) têm a respeito dos processos de ensino e aprendizagem de línguas. Alguns exemplos de crenças de alunos são: (a) que só se deve aprender uma língua estrangeira nos países onde essa língua é falada (Barcelos, 1995; Carvalho, 2000); (b) que é possível aprender uma língua estrangeira em pouco

\footnotetext{
${ }^{2}$ O objetivo desta resenha é revisão sobre metodologia de investigação das crenças sobre aprendizagem de línguas de alunos ou aprendizes. Devido a limitações de espaço e tempo, a discussão sobre o conceito de crenças é bem breve. Para uma discussão mais aprofundada a respeito da definição de crenças em geral, consultar Abelson (1979), Nespor (1987) e Pajares (1992). Sobre crenças a respeito de aprendizagem de línguas, consultar Barcelos (2000). Para uma revisão de estudos a respeito de crenças de professores sobre aprendizagem de línguas, ver Gimenez (1994).
} 
tempo; e (c) que a língua portuguesa é mais difícil do que a língua inglesa (Viana, 1993). As crenças são pessoais, contextuais, episódicas e têm origem nas nossas experiências, na cultura ${ }^{3}$ e no folclore. As crenças também podem ser internamente inconsistentes e contraditórias.

Uma das mais importantes características das crenças refere-se a sua influência no comportamento. De acordo com Pajares (1992), as crenças influenciam como as pessoas organizam e definem suas tarefas. Em outras palavras, elas são fortes indicadores de como as pessoas agem. $\mathrm{Na}$ literatura em LA, a relação entre crenças e ações refere-se à maneira como as crenças podem influenciar a abordagem dos alunos em relação à aprendizagem - "como eles percebem e interpretam sua aprendizagem" (Richards \& Lockhart, 1994: 58) e as estratégias de aprendizagem que eles adotam e usam (Horwitz, 1987; Wenden, 1987).

Vários pesquisadores sugerem que as crenças sobre aprendizagem de línguas podem influenciar as estratégias de aprendizagem de línguas $^{4}$ (Abraham \& Vann, 1987; Erlbaum et al., 1993; Riley, 1997; Yang, 1992). Riley (1997) afirma que as crenças sobre aprendizagem de línguas podem influenciar diretamente a motivação, as atitudes e os tipos de estratégias utilizadas pelos alunos. Assim, de acordo com Riley, os alunos que acreditam poder aprender somente na presença de um professor terão problemas com qualquer tipo de ensino autônomo. Abraham e Vann (1987) explicam que a filosofia dos alunos serve de guia para a abordagem que eles adotam em relação à aprendizagem de línguas. Essa filosofia pode se manifestar em "estratégias observáveis (e não observáveis) e influenciar diretamente o grau de sucesso que os aprendizes atingem" (Abraham e Vann 1987: 96). Existem alguns estudos, que investigaram a relação entre as crenças e as estratégias de aprendizagem, dentre os quais destaco o de Yang (1992).

Yang (1992) investigou a relação entre as crenças e estratégias de aprendizagem de línguas. Seus resultados indicaram que as crenças

\footnotetext{
${ }^{3}$ Cultura, neste sentido, vai além da definição tradicional referente às regras de comportamento de determinadas naçōes para englobar qualquer "agrupamento social mais ou menos estabelecido que constrói suas próprias regras de comportamento, interação e socialização no decorrer de contato intensivo e prolongado" (Ramanathan \& Atkinson, 1999: 49).

${ }^{4} \mathrm{O}$ conceito de estratégias de aprendizagem adotado neste trabalho é de acordo com Oxford (1990: 1): "ações que os alunos tomam para melhorar sua própria aprendizagem" (tradução minha).
} 
sobre aprendizagem de línguas parecem afetar o uso de estratégias de aprendizagem. Mais especificamente, a auto-eficácia e a expectativa dos alunos a respeito de ensino e aprendizagem de línguas foram associadas com o uso de estratégias voltadas para a prática da língua com ênfase na comunicação e no significado. A percepção dos alunos sobre o valor de aprender habilidades orais na língua inglesa estava relacionada com o uso dessas estratégias. Resultados similares a esses foram encontrados também por Erlbaum et al. (1993) e Wenden (1987).

Apesar de ter sugerido que as crenças podem guiar o comportamento, Yang (1992: 148) afirma que "as crenças dos aprendizes podem causar estratégias, mas o uso de estratégias pode também causar crenças". Murphey (1996) concorda com Yang. Murphey acredita que essa relação é recíproca, ou seja, as crenças podem influenciar as estratégias de aprendizagem, mas o uso de certas estratégias pode, por sua vez, influenciar a formação de algumas crenças. $\mathrm{O}$ autor afirma que nossas ações podem influenciar e mudar nossas crenças. Para ele, desde que haja tempo e modelo adequado, as crenças podem ser modificadas, se conseguirmos mudar primeiro o comportamento.

Como se pode perceber pela discussão acima, os estudos têm se limitado a investigar o tópico, estabelecendo uma relação de causa e efeito entre crenças e comportamento. Entretanto, não temos dados suficientes ainda para afirmar a natureza dessa correlação. A correlação entre crenças e comportamento certamente existe, mas ela depende de vários fatores como experiência anterior de aprendizagem dos alunos, abordagem de ensinar do professor, nível de proficiência, motivação e contexto. A relação entre crenças e ações é complexa e requer uma definição de ação mais ampla, que elimine a dicotomia ação/pensamento. Tal definição encontra-se na filosofia de John Dewey (1933) que caracterizou ação como intencional e proposital e intrinsicamente relacionada com o pensamento. Dessa maneira, para entender as crenças precisamos entender não somente as intenções, mas também "os significados intersubjetivos que permeiam os pensamentos e ações" (Schwandt, 1997: 65). Essa definição de ação requer uma abordagem de investigação mais interativa, que leve em consideração a reciprocidade entre crenças e ações. De acordo com Pajares (1992), Richardson (1996) e Rokeach (1968), as crenças devem ser inferidas não somente através das afirmações verbais dos participantes, mas também através de suas intenções e ações. Os estudos atuais a respeito de crenças sobre aprendizagem não têm consi- 
derado esse aspecto, conforme sugere a seção seguinte de revisão dos diferentes estudos sobre a metodologia de investigação das crenças.

\section{Abordagens de investigação das crenças sobre aprendizagem de línguas}

Em sua revisão a respeito de crenças sobre aprendizagem de línguas, Kalaja (1995: 192) critica estudos atuais sobre crenças, apontando que, até o momento, as crenças têm sido vistas principalmente como "entidades cognitivas encontradas dentro da mente dos aprendizes de língua" e têm sido caracterizadas como estáveis. Kalaja discorda dessa caracterização e aponta estudos como o de Holec (1987) que sugere que as crenças podem ser modificadas. A autora propõe, então, uma abordagem para a investigação das crenças que inclui pressupostos básicos de que o uso da linguagem é orientado para a ação, que a linguagem cria realidade e que tanto o conhecimento científico quanto as concepções leigas são "vistos como construções sociais do mundo" (Kalaja, 1995: 196).

Dentro dessa perspectiva, Kalaja define crenças como construídas socialmente, interativas, sociais e variáveis. De acordo com a autora, as crenças podem mudar de um aluno para outro, de uma época para outra, e de um contexto para outro, ou até mesmo dentro de um mesmo contexto ou ocasião. Para ela, as crenças devem ser investigadas através de "trechos de fala" ou escrita sobre aspectos de aquisição de segunda língua (Kalaja,1995: 196). O paradigma proposto por Kalaja oferece uma perspectiva interessante na investigação das crenças, caracterizadas como dinâmicas, sociais e relacionadas à linguagem. Infelizmente, existem poucos estudos publicados dentro desse paradigma.

Diferentemente de Kalaja, que reconhece apenas duas abordagens de investigação a respeito das crenças sobre aprendizagem de línguas, neste trabalho, agrupo os estudos em três abordagens principais de acordo com a sua definição de crenças, metodologia, e relação entre crenças e ações. A primeira abordagem, chamada de abordagem normativa, infere as crenças através de um conjunto pré-determinado de afirmações. A segunda abordagem, metacognitiva, utiliza auto-relatos e entrevistas para inferir as crenças sobre aprendizagem de línguas. A terceira abordagem, contextual, usa ferramentas etnográficas e entrevistas para investigar as crenças através de afirmações e ações. A análise do 
discurso também pode ser incluída nessa abordagem. Nas próximas seções, cada abordagem é discutida separadamente.

\section{A abordagem normativa}

O termo "normativo" foi usado por Holliday (1994), para se referir a estudos sobre cultura, os quais vêem a cultura dos alunos como explicação para suas ações em sala de aula. Da mesma forma, os estudos incluídos nessa abordagem colocam as crenças como indicadores dos comportamentos futuros dos alunos como bons aprendizes ou como aprendizes autônomos.

A abordagem normativa inclui estudos que usam questionários do tipo Likert-scale para investigar as crenças. Esse tipo de questionário contém afirmações com alternativas que vão desde "eu concordo inteiramente" até "eu discordo inteiramente". 5 O questionário mais usado é o Beliefs About Language Learning Inventory (BALLI), que foi desenvolvido por Horwitz (1985). A maioria dos estudos nesta abordagem ora usa o BALLI (Horwitz, 1987, 1988; Su, 1995; Tumposky, 1991; Yang, 1992) ora o adapta ou modifica (Mantle-Bromley, 1995). Outros estudos desenvolvem seus próprios questionários (Campbell et. al., 1993; Cotterall, 1995; Sakui \& Gaies, 1999; Kuntz, 1996; Mori, 1997; Wen \& Johnson, 1997).

Os estudos incluídos na abordagem normativa, em geral, descrevem e classificam os tipos de crenças que os aprendizes apresentam. A maioria desses estudos faz conexões entre as crenças e o ensino autônomo. O estudo de Cotterall (1995) teve por objetivo determinar os fatores nas crenças dos alunos que indicariam sua prontidão para o ensino autônomo. Ela construiu um questionário tipo Likert-scale a partir das entrevistas com 130 aprendizes adultos de inglês como segunda língua em universidades na Nova Zelândia. Seis fatores foram encontrados: o papel do professor, o papel do feedback, a independência do aprendiz, a confiança do aprendiz na sua capacidade de estudo, a experiência de aprendizagem de línguas e a

\footnotetext{
${ }^{5}$ Para uma discussão a respeito de questionários com escala Likert, consultar Low (1988) e Luppescu \& Day (1990). Para uma discussão sobre o BALLI, ver Kuntz (1996).
} 
abordagem de estudar. Os resultados indicaram que os alunos não estavam "prontos" para o ensino autônomo, porque eles tinham visões tradicionais do papel do professor (embora a definição de 'tradicional' não tenha sido discutida no texto). Os comentários de Cotterall (1995: 197) enfatizam as crenças dos alunos como obstáculos no processo de aprendizagem autônoma: "aprendizes [...] não correspondem ao perfil do aprendiz autônomo", "as expectativas dos alunos sobre a autoridade do professor podem representar um obstáculo para os professores" (p. 197), "aprendizes que acreditam que o professor deve fazer tudo [...] ainda não estão prontos para a autonomia" (Cotterall, 1995: 198, ênfase minha). Esses tipos de comentários sugerem uma visão ideal do aprendiz à qual os "alunos reais" não correspondem (Benson, 1995).

Alguns estudos têm incluído entrevistas como uma maneira de validar o uso de questionários. As entrevistas geralmente apontam que os aprendizes possuem crenças que são diferentes daquelas apresentadas no BALLI. Sakui e Gaies (1999), além de usarem um questionário com escalas Likert, usaram entrevistas em sua investigação a respeito das crenças de alunos japoneses. Os resultados das entrevistas sugeriram que as crenças sobre aprendizagem de línguas são contextuais e podem mudar. Assim, as discrepâncias encontradas nos questionários não devem ser vistas como "erros". Sakui e Gaies afirmam que os alunos interpretam os itens dos questionários de maneira diferente e podem querer descrever suas crenças de maneira que o questionário não permite.

Em resumo, na abordagem normativa, as crenças sobre aprendizagem de línguas são definidas como opiniões que os alunos possuem sobre aprendizagem de línguas que influenciam sua abordagem de aprendizagem ou sua prontidão para o ensino autônomo. Em alguns estudos, as crenças dos alunos são caracterizadas como concepções errôneas, isto é, como obstáculos à implementação de determinados tipos de abordagem, em geral, do ensino autônomo. Retratam-se as crenças dos alunos como inadequadas, mas não se explicita muito bem, sob que perspectiva. O método de investigação mais comumente adotado é o questionário com escalas tipo Likert, em que os alunos apenas dizem se concordam ou não com afirmações pré-estabelecidas pelos pesquisadores. A relação entre crenças e ações não é investigada, mas apenas sugerida. Em sua maioria, as crenças são vistas como obstáculos para ações que os aprendizes deveriam adotar, pelo menos de acordo com a visão dos pesquisa- 
dores. Não existe uma análise do contexto onde os alunos agem e interagem.

\section{Vantagens e desvantagens}

Questionários têm sido largamente utilizados na investigação das crenças e oferecem várias vantagens. Eles são menos ameaçadores que observações, são úteis se o pesquisador tem recursos limitados e pouco tempo, "são fáceis de tabular e particularmente adequados para um grande número de participantes" (Gimenez, 1994: 76). Além disso, os questionários fornecem acesso a outros contextos e permitem que os dados sejam coletados em épocas diferentes (McDonough \& McDonough, 1997). Entretanto, questionários apresentam algumas desvantagens.

Em primeiro lugar, os questionários tornam difícil garantir uma interpretação consistente pelos participantes, por causa de sua generalidade. Além disso, os participantes tendem a responder o que eles acham que seria adequado (Gimenez, 1994). Em segundo lugar, os questionários restringem a escolha dos participantes quando estruturam as respostas de acordo com um conjunto de afirmações pré-estabelecidas. Ao não permitir que os alunos usem suas próprias palavras e metáforas, os questionários tornam difícil investigar as crenças nos termos dos próprios alunos e professores (Block, 1997, 1998; Cortazzi \& Jin, 1996; Gimenez, 1994; Kalaja 1995; Kuntz, 1996; Munby, 1984; Pajares, 1992; Riley, 1996; Woods, 1996). Wenden (1987) também apontou que questionários não permitem que os alunos articulem seu conhecimento metacognitivo.

Em resumo, na abordagem normativa, as crenças são descontextualizadas. Isto é problemático, primeiro porque os alunos podem interpretar os itens dos questionários de maneira diferente do que o pesquisador pretendia, conforme exposto acima. Em segundo lugar, as crenças apresentadas no questionário podem ser diferentes das crenças que os alunos acreditam ser significativas em sua aprendizagem. Em terceiro lugar, se os alunos têm algumas daquelas crenças, o que isso significa? Eles agem de acordo com aquelas crenças? Como eles interagem com essas crenças? Porque eles têm essas crenças? A abordagem metacognitiva, discutida a seguir, dá mais importância à linguagem dos alunos ao thes proporcionar a chance de refletir e falar sobre suas experiências de aprendizagem em entrevistas. 


\section{A abordagem metacognitiva}

Os estudos nessa abordagem definem crenças como conhecimento metacognitivo, daí o nome da abordagem. Os estudos incluídos aqui utilizam-se basicamente de entrevistas semi-estruturadas e auto-relatos, embora questionários semi-estruturados possam ser usados (cf. Victori, 1992). O que une os estudos nessa abordagem é a definição de crenças como conhecimento metacognitivo. O pressuposto implícito nessa abordagem é que o conhecimento metacognitivo dos alunos se constituem em suas "teorias em ação" que os ajudará a refletir sobre o que fazem e a desenvolver seu potencial para a aprendizagem (Wenden, 1987: 112).

Existem poucos estudos nessa abordagem (até agora, somente Wenden, 1987; Victori, 1992; Victori \& Lockhart, 1995). A maioria dos estudos tem como referencial teórico o conhecimento cognitivo e sua influência na aprendizagem (ver Wenden, 1986, 1991, 1999). O pressuposto básico nesses estudos é que os aprendizes pensam sobre seu processo de aprendizagem de línguas e são capazes de articular algumas de suas crenças. Wenden (1986) descobriu que os aprendizes são capazes de falar sobre a língua, sua proficiência na língua, os resultados de seus esforços na aprendizagem, seu papel no processo de aprendizagem de línguas e a melhor maneira de aprender línguas.

Wenden (1987: 163) define conhecimento cognitivo como o conhecimento "estável, declarável, embora às vezes incorreto, que os aprendizes têm sobre linguagem, aprendizagem, e aprendizagem de línguas". A autora caracteriza esse conhecimento como falível, ou seja, nem sempre empiricamente sustentável, e interativo, isto é, que pode influenciar os resultados da aprendizagem.

Wenden (1987) investigou as crenças prescritivas dos aprendizes a fim de saber se eles tinham esses tipos de crenças, quais eram essas crenças e se elas refletiam-se no que os aprendizes diziam fazer para aprender uma segunda língua. A autora define crenças prescritivas como crenças dos aprendizes sobre a melhor maneira de se aprender uma segunda língua. Ela entrevistou 25 alunos que moravam nos Estados Unidos por dois anos e estavam matriculados em níveis avançados em um instituto de línguas. Os resultados mostraram que os alunos tinham crenças prescritivas sobre (a) a importância de usar a língua de uma maneira natural, isto é, praticando, pensando em inglês, morando e estudando onde o inglês é falado; (b) a importância de aprender sobre a língua, sua 
gramática e seu vocabulário, aprender com os erros e estar mentalmente ativo; e (c) a importância de fatores pessoais (sentimentos, auto-conceito, atitude e aptidão). Ao comparar as crenças de seu estudo com aquelas usadas no questionário BALLI, Wenden constatou que algumas eram bem diferentes, enquanto outras não estavam representadas no BALLI. Em sua conclusão, Wenden faz uma crítica sutil aos questionários, afirmando que essas "diferenças apontam para a necessidade de se desenvolver um questionário mais abrangente e representativo do conjunto de crenças" (Wenden, 1987: 113).

Os estudos dentro dessa abordagem definem crenças como conhecimento metacognitivo, caracterizado por Wenden (1987) como conhecimento estável e falível. Nesse sentido, é semelhante à definição da abordagem normativa, pois também vê as crenças como obstáculo a uma determinada visão de aprendizagem. A metodologia não envolve o uso de questionários Likert-scale, como o BALLI, mas o uso de entrevistas, que são analisadas de acordo com seu conteúdo, e podem envolver também o uso de questionários semi-estruturados. A relação entre crenças e ação também não é investigada, mas apenas sugerida e discutida somente em relação a estratégias de aprendizagem.

\section{Vantagens e Desvantagens}

As vantagens da abordagem metacognitiva são várias. Em primeiro lugar, através do uso de entrevistas, os alunos têm a oportunidade de elaborar e refletir sobre suas experiências. De acordo com Block (1997), entrevistas permitem aos alunos definir e avaliar o processo de aprendizagem em seus próprios termos. Em segundo lugar, na abordagem metacognitiva, as crenças são consideradas como conhecimento. Isso implica o reconhecimento das crenças dos alunos como parte de seu processo de raciocínio. Apesar de tais vantagens, a abordagem metacognitiva não infere as crenças através das ações, mas somente através de intenções e declarações verbais. Além disso, embora haja o reconhecimento da relação entre crenças e contexto, essa relação e sua influência nas crenças dos alunos não são consideradas ou analisadas.

\section{A abordagem contextual}

Mais recentemente, alguns estudos começaram a investigar as crenças sob uma perspectiva diferente. Esses estudos não utilizam questionários nem definem crenças como conhecimento cognitivo. As cren- 
ças são investigadas através de observações de sala de aula e análise do contexto ${ }^{6}$ específico onde os alunos atuam, daí o nome dessa abordagem. Esses estudos não têm como objetivo generalizar sobre as crenças, mas compreender as crenças de alunos (ou professores) em contextos específicos.

Os estudos incluídos nessa abordagem caracterizam crenças como específicas de um determinado contexto (Allen, 1996) ou de uma cultura de aprender de um determinado grupo (Barcelos, 1995; Garcia, 1999). Os estudos, em sua maioria, procuram considerar a influência da experiência anterior de aprendizagem de línguas dos alunos não somente em suas crenças, mas também em suas ações dentro de um contexto específico. Dentre os estudos dessa abordagem, destaco o estudo de Allen (1996). Allen investigou a influência das crenças sobre aprendizagem de línguas do professor nas crenças estabelecidas de um aprendiz. Ela também examinou se e como os comportamentos, as estratégias e as percepções do aluno sobre seu próprio sucesso na aprendizagem de línguas foram afetados como resultado dessa influência. O participante da pesquisa foi um libanês, aluno de nível intermediário de inglês, no Carleton School of Linguistics, no Canadá. A metodologia incluiu observações de sala de aula, entrevistas com professor e aluno e anotações em seus diários. Allen também analisou o livro-texto, as apostilas e os materiais adicionais preparados pelo professor.

Os resultados indicaram que as crenças do professor influenciaram as crenças do aluno. A princípio, o aluno acreditava que o professor deveria ser o responsável por sua aprendizagem, que a interação com falantes nativos era melhor para sua aprendizagem e que ele deveria ter uma pronúncia mais perto possível da nativa. O professor acreditava que os alunos eram responsáveis por sua aprendizagem e que não deveriam ter uma pronúncia similar à dos nativos. Ao final do semestre, as crenças do aluno tornaram-se mais similares às do seu professor, $\mathrm{e}$ isso afetou a percepção do aluno sobre seu sucesso na aprendizagem e as estratégias uti-

\footnotetext{
${ }^{6}$ A definição de contexto neste trabalho não se refere a "um recipiente estático que circunda a interação social" (Lave, 1993: 22). Contexto é definido neste estudo como "um fenômeno socialmente constituído e sustentado interativamente" onde "cada ação acrescentada dentro da interação modifica o contexto existente enquanto cria uma nova arena para interações subseqüentes" (Goodwin \& Duranti, 1992:.5-6). De acordo com essa definição, as perpectivas dos participantes e a maneira como eles organizam suas percepções dos eventos são essenciais.
} 
lizadas por ele. O estudo de Allen (1996) mostra, primeiro, que as crenças estão inter-relacionadas com as experiências dos alunos e segundo, que as crenças não são tão estáveis como se costuma pensar. Conforme sugerido por Valenzuela (1996), uma boa abordagem para inferir crenças envolve sua investigação através de ângulos diferentes, combinando observações e entrevistas.

Na abordagem contextual, as crenças são caracterizadas como dependentes do contexto. A metodologia utilizada envolve o uso de entrevistas e principalmente observações de sala de aula. Esse é o ponto que difere essa abordagem das outras. Assim, a relação entre crenças e ação não é somente sugerida, mas é investigada dentro do contexto específico dos alunos.

\section{Vantagens e desvantagens}

A abordagem contextual oferece uma definição mais ampla de crenças sobre aprendizagem de línguas, caracterizando-as como dinâmicas e sociais, e propondo uma metodologia diferente para investigá-las. Essa metodologia fornece uma riqueza de detalhes bem mais refinados a respeito dos tipos de crenças e do contexto onde essas crenças se desenvolvem, permitindo, assim, uma maior compreensão das crenças e de sua relação com a abordagem de aprender línguas estrangeiras dos alunos. Além disso, ao retratar os aprendizes como agentes sociais interagindo em seus contextos, essa abordagem também apresenta uma visão mais positiva do aprendiz do que as abordagens normativa e metacognitiva. Entretanto, estudos desse tipo podem consumir muito tempo e são mais adequados às investigações com menor número de participantes. A Tabela 1 resume as características, vantagens e desvantagens de cada abordagem.

Tabela 1: Características, vantagens, e desvantagens das três abordagens

\begin{tabular}{|c|c|c|c|}
\hline & Normativa & Metacognitiva & Contextual \\
\hline Metodologia & $\begin{array}{l}\text { Questionários tipo } \\
\text { Likert-scale. }\end{array}$ & Entrevistas & $\begin{array}{l}\text { Observaçōes, } \\
\text { entrevistas, diários, e } \\
\text { estudos de caso. }\end{array}$ \\
\hline $\begin{array}{l}\text { Definição de crenças } \\
\text { sobre aprendizagem de } \\
\text { linguas }\end{array}$ & $\begin{array}{l}\text { Crenças sāo vistas como } \\
\text { sinōnimos de idéias pre- } \\
\text { concebidas, concepções } \\
\text { errôneas e opiniões. }\end{array}$ & $\begin{array}{l}\text { Crenças săo descritas } \\
\text { como conhecimento } \\
\text { metacognitivo: estável e } \\
\text { às vezes falivel que os } \\
\text { aprendizes possuem } \\
\text { sobre aprendizagem de } \\
\text { línguas. }\end{array}$ & $\begin{array}{l}\text { Crenças sāo vistas como } \\
\text { parte da cultura de } \\
\text { aprender e como } \\
\text { representaçōes de } \\
\text { aprendizagem em uma } \\
\text { determinada sociedade. }\end{array}$ \\
\hline
\end{tabular}




\begin{tabular}{|c|c|c|c|}
\hline $\begin{array}{l}\text { Relaçāo entre crenças } \\
\text { e ações }\end{array}$ & $\begin{array}{l}\text { Crenças são vistas como } \\
\text { bons indicadores do } \\
\text { comportamento tuturo } \\
\text { dos alunos, sua } \\
\text { disposiçāo para ensino } \\
\text { autônomo e sucesso } \\
\text { como aprendizes de } \\
\text { língua. }\end{array}$ & $\begin{array}{l}\text { Crenças são vistas como } \\
\text { bons indicadores do } \\
\text { comportamento futuro } \\
\text { dos alunos, sua } \\
\text { disposição para ensirio } \\
\text { autônomo e sucesso } \\
\text { como aprendizes de } \\
\text { língua, embora admita- } \\
\text { se a influência de outros } \\
\text { fatores como objetivos, } \\
\text { por exemplo. }\end{array}$ & $\begin{array}{l}\text { Crenças sâo vistas como } \\
\text { específicas do contexto, } \\
\text { ou seja, as crenças } \\
\text { devem ser investigadas } \\
\text { dentro do contexto de } \\
\text { suas açōes. }\end{array}$ \\
\hline Vantagens & $\begin{array}{l}\text { Permite que as crenças } \\
\text { sejam investigadas com } \\
\text { amostras grandes, em } \\
\text { épocas diferentes e em } \\
\text { vários contextos ao } \\
\text { mesmo tempo. }\end{array}$ & $\begin{array}{l}\text { Permite que os alunos } \\
\text { usem suas próprias } \\
\text { palavras, elaborem e } \\
\text { reflitam sobre suas } \\
\text { experiências de } \\
\text { aprender. }\end{array}$ & $\begin{array}{l}\text { Permite que as crenças } \\
\text { sejam investigadas } \\
\text { levando em } \\
\text { consideração nảo só as } \\
\text { próprias palavras dos } \\
\text { alunos, mas também o } \\
\text { contexto de suas açōes. }\end{array}$ \\
\hline Desvantagens & $\begin{array}{l}\text { Restringe a escolha dos } \\
\text { participantes com um } \\
\text { conjunto de afirmaçōes } \\
\text { predeterminadas pelo } \\
\text { pesquisador. Os alunos } \\
\text { podem ter interpretaçōes } \\
\text { diferentes sobre esses } \\
\text { itens. }\end{array}$ & $\begin{array}{l}\text { As crenças são } \\
\text { investigadas somente } \\
\text { através das afirmaçōes } \\
\text { dos alunos (nāo há } \\
\text { preocupaçāo com a ação } \\
\text { dos alunos). }\end{array}$ & $\begin{array}{l}\text { É mais adequada com } \\
\text { pequeno número de } \\
\text { participantes. Consome } \\
\text { muito tempo. }\end{array}$ \\
\hline
\end{tabular}

\section{Discussão e conclusão}

Neste trabalho, foi feita uma revisão crítica da metodologia de investigação sobre crenças a respeito de aprendizagem. Sugeriu-se a existência de três abordagens: a normativa, a metacognitiva e a contextual. As diferentes metodologias indicam a concepção implícita de crenças utilizadas por vários estudos.

Enquanto na abordagem normativa as crenças são definidas, em geral, como concepções errôneas e são investigadas de uma maneira descontextualizada, na abordagem metacognitiva as crenças são investigadas através de entrevistas, dando aos alunos mais chances de usarem suas próprias palavras e de contarem suas próprias estórias. Entretanto, tanto a abordagem normativa quanto a metacognitiva consideram crenças como uma característica mental, como apontado por Kalaja (1995). Não se quer dizer com isso que as crenças não tenham um componente cognitivo, mas não se deve esquecer também que as crenças, assim como o conhecimento, estão embutidas no contexto. Uma definição de crenças que leve em consideração o contexto seria essencial na compreensão do papel que as crenças exercem na experiência de aprendizagem de línguas dos alunos. 
Em resumo, tanto a abordagem normativa quanto a metacognitiva falham em levar em consideração a natureza experiencial das crenças, por (a) não analisar as crenças dos alunos nos seus próprios termos; (b) tratar as crenças como um conceito fixo a-priori; e (c) não prestar atenção ao contexto social das crenças.

É importante notar, entretanto, que, na prática, as distinções entre as três abordagens podem não ser tão distintas. As escolhas metodológicas freqüentemente dependem dos tipos de perguntas de pesquisa. Além disso, trabalhos recentes como os Carvalho (2000) e Sakui \& Gaies (1999) combinam diferentes instrumentos de coleta como, por exemplo, o uso de questionários com escalas do tipo Likert e entrevista. Outra maneira de visualizar as três abordagens é dentro de um contínuo de dois pólos que representam categorias a priori ou embasadas (grounded), que dizem respeito à maneira como os dados são coletados e analisados. Assim, a abordagem normativa se utiliza de categorias $a$ priori de análise, ou seja, pré-determinadas, enquanto a abordagem contextual emprega categorias embasadas, ou seja, permite que o sentido emerja dos dados (Freeman, 1996). A abordagem metacognitiva encontra-se entre essas duas categorias com maior proximidade com a categoria a-priori, conforme ilustra a Figura 1.

\section{Figura 1: Abordagens de investigação e categorias de análise}

\begin{tabular}{lcc} 
Normativa & Metacognitiva & Contextual \\
\hline Categorias a priori & 1 \\
\hline
\end{tabular}

Os estudos atuais descrevem os tipos de crenças que os alunos podem ter e apontam para a importância desse tópico em LA. Entretanto, a falta de mais estudos embasados não tem ajudado a entender como os alunos na verdade usam as crenças para interpretar situações diferentes e tomar decisões em seu processo de aprendizagem (Woods, 1997). Alguns trabalhos da abordagem contextual já investigam esse aspecto, mas ainda se sabe muito pouco sobre as funções que as crenças exercem na aprendizagem de línguas. Alguns pesquisadores já sugeriram que entrevistas abertas e observações de sala de aula podem nos ajudar a ter uma visão bem mais precisa a respeito das crenças (Kern, 1995; Pajares, 1992; Press, 1996). 
Estudos recentes têm combinado abordagens múltiplas, usando questionários com observações de sala de aula (Mantle-Bromley, 1995) e com entrevistas (Sakui \& Gaies, 1999; Wen \& Johnson, 1997). Outros estudos utilizam análise metafórica, diários e narrativas (Ellis, 1998; Miller \& Ginsberg, 1995), desenhos (Swales, 1994) e estudos de caso (Allen, 1996; Valenzuela, 1996). Esses estudos mais embasados permitem que 0 sentido emerja do contexto e indicam a importância de se examinar a relação entre as crenças dos alunos e suas ações em contexto. Vários autores sugerem que as crenças são formadas pela cultura do alunos e pelos contextos sociais nos quais eles estão inseridos (Barcelos, 1995; Riley, 1997; Tumposky, 1991; Yang, 1992). Além disso, as crenças são variáveis (Sakui \& Gaies, 1999; Kalaja, 1995) e construídas socialmente (Kalaja, 1995).

Embora as três abordagens sejam diferentes no modo de definir e investigar as crenças, todas elas enfatizam que as crenças influenciam o comportamento, definido, em LA, como as estratégias de aprendizagem ou abordagem de aprendizagem dos alunos (Abraham \& Vann, 1987; Horwitz, 1985, 1987, 1988; Mantle-Bromley, 1995; Wenden, 1987). Entretanto, a relação entre crenças e ações não é tão direta (Riley, 1997; Yang, 1992). As crenças não somente influenciam ações, mas as ações e reflexões sobre experiências podem levar a mudanças ou criar outras crenças (Murphey, 1996; Richardson, 1996), conforme ilustra a Figura 2.

\section{Figura 2: Relação entre crenças e ações}

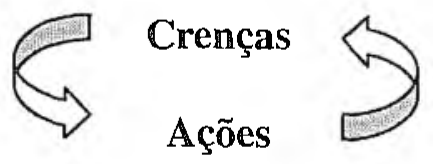

De acordo com Riley (1997: 141), os pesquisadores devem "olhar para as condições de aprendizagem onde os aprendizes se encontram" para entender suas crenças sobre aprendizagem de línguas. Em resumo, as crenças devem ser investigadas de maneira interativa, onde crenças e ações se inter-relacionem e se interconectem.

\section{Perguntas e sugestões para pesquisas futuras a respeito de crenças sobre aprendizagem de línguas}

Várias questões a respeito de crenças sobre aprendizagem de línguas podem ser mais bem investigadas em trabalhos futuros. Em primei- 
ro lugar, como se desenvolvem as crenças sobre aprendizagem de línguas? Estudos mais longitudinais podem mostrar como as crenças evoluem e mudam com o passar do tempo. Estudos interpretativos podem levar a uma compreensão mais aprofundada sobre as crenças. É crucial entender como as experiências pessoais dos alunos contribuem para moldar suas crenças e suas ações no contexto social da aula de língua estrangeira. Observações de aula e entrevistas detalhadas de alunos e professores podem ajudar a contextualizar aspectos encontrados em dados quantitativos (Sakui \& Gaies, 1999; Kern, 1995; Press, 1996). Mais importante ainda é considerar que estudos interpretativos poderão dar uma visão mais aprofundada de como as experiências de aprender dos alunos, em contextos diferentes no Brasil, tais como escolas públicas, "cursinhos de inglês", e no exterior, influenciam os tipos de crenças que esse alunos têm sobre como aprender inglês e suas ações para aprender nesses contextos diferentes.

Em segundo lugar, como as crenças podem ser modificadas? Wenden (1991) sugere um plano para explorar as crenças dos aprendizes. Até o momento, não existe estudo empírico que tenha tentado mudar as crenças dos aprendizes ou incorporar uma discussão sobre crenças a respeito de aprendizagem de línguas em atividades de sala de aula, levando os alunos a uma aprendizagem reflexiva. A aprendizagem reflexiva, de maneira semelhante ao conceito de ensino reflexivo dos professores, diz respeito à conscientização dos alunos sobre como eles aprendem uma língua estrangeira. Aprender reflexivamente significa abrir a discussão a respeito de crenças, estratégias e estilos de aprendizagem aos alunos, para que eles mesmos possam refletir entre eles e com seus professores sobre sua cultura de aprender, sobre crenças de aprendizagem de línguas e como elas influenciam suas ações para aprender dentro e fora de sala de aula. Estudos futuros devem incorporar a discussão a respeito de crenças sobre aprendizagem de línguas em atividades de sala de aula dando oportunidade a alunos e professores de línguas de discutir e refletir não somente sobre suas próprias crenças, mas também sobre obstáculos, dentro e fora da sala de aula de línguas, que possam impedilos de agir de acordo com suas próprias crenças e de desenvolver seu potencial para ensino e aprendizagem. ${ }^{7}$

\footnotetext{
${ }^{7}$ Barcelos (2000a) e Murphey (1997) oferecem algumas sugestões de atividades relacionadas às crenças que podem ser exploradas em sala de aula.
} 
Finalmente, quais as funções que as crenças exercem nas experiências de aprendizagem dos alunos e nas ações que eles praticam para aprender línguas? Não sabemos ainda como os alunos usam suas crenças para lidar com a complexidade da aprendizagem de línguas, ou seja, se os alunos definem seu próprio contexto e atuam nele, nós precisamos entender como as crenças os ajudam a fazer isso e a "navegar" no discurso da sala de aula de línguas (Breen, 1996). Pesquisas futuras devem investigar como a sala de aula de línguas, como um contexto social, ajuda a moldar as crenças dos alunos e como as crenças dos alunos, por sua vez, moldam a interação e as ações que ocorrem na cultura da sala de aula.

A pesquisa a respeito de crenças sobre aprendizagem de línguas precisa ir além da simples descrição de crenças como indicadores de um comportamento futuro. É preciso uma investigação contextualizada das crenças. É necessário entender como as crenças interagem com as ações dos alunos e que funções elas exercem em suas experiências de aprendizagem dentro e fora de sala de aula. Como Dewey (1933) sugeriu, o conhecimento não pode estar separado da ação. Assim, uma investigação do que os alunos sabem ou acreditam deve envolver (a) suas experiências e ações; (b) suas interpretações sobre essas experiências; e (c) o contexto social e como esse contexto molda as suas experiências.

\section{Referências Bibliográficas}

ABELSON, R. P. Difference between belief and knowledge systems. Cognitive Science, 3, p. 355-366, 1979.

ABRAHAM, R. G.; VANN, R. J. Strategies of two language learners: A case study. In:

WENDEN, A.; RUBIN, J. (Ed.). Learner strategies in language learning. Londres: Prentice Hall, 1987. p. 85-102.

ALLEN, L. The evolution of a learner's beliefs about language learning. Carleton Papers in Applied Language Studies, XIII, p. 67-80,1996.

BARCELOS, A. M. F. A cultura de aprender lingua estrangeira (inglês) de alunos de Letras. 1995. 188f. Dissertação (Mestrado em Linguística Aplicada) - Instituto de Estudos da Linguagem, UNICAMP, Campinas. 
Current Approaches to the Investigation of Language Learning Beliefs: A Literature Review. In: AILA'99, 1999, Tóquio. 12 ${ }^{\text {th }}$ World Congress of Applied Linguistics AILA'99 - Programa and Abstracts, Tóquio: AllA, 1999. p. 133.

. Understanding teachers' and students' language learning beliefs in experience: A Deweyan Approach. 2000. 357f. Tese (Doutorado em Ensino de Inglês como Segunda Língua). College of Education, The University of Alabama, Tuscaloosa.

Incorporating language learning beliefs in the classroom - Workshop. União Cultural Brasil Estados Unidos, São Paulo, 3 de agosto, 2000a.

BENSON, P. A critical view of learner training. Learning Learning, v. 2, n .2, p. 2-6, 1995.

BLOCK, D. Learning by listening to language learners. System, v. 25, n. 3, p. 347-360, 1997.

BLOCK, D. Exploring interpretations of questionnaire items. System, v. 26, n. 3, p. 403-425, 1998.

BREEN, M. Constructions of the learner in second language acquisition research. In:

ALATIS, J.; STRAEHLE, C.; RONKIN, M.; GALLENBERGER, B. (Ed.). Georgetown University Round Table on Languages and Linguistics. Washington: Georgetown University Press, 1996. p. 84-115.

CARVALHO, V. C. P. S. A aprendizagem de língua estrangeira sob a ótica de alunos de letras: crenças e mitos. 2000. 138f. Dissertação (Mestrado em Estudos Lingüísticos) - Faculdade de Letras, UFMG, Belo Horizonte.

CAMPBELL, C. M.; SHAW, V. M.; PLAGEMAN, M.E.; ALLEN, T. A. Exploring student beliefs about language learning. In: HATFIELD, W. N. (Ed.). Visions and realities in foreign language teaching: where we are, where we are going. Lincolnwood: National Textbook, 1993. p. 29-39.

CORTAZZI, M. \& JIN, L. Cultures of learning: Language classrooms in China. In:

COLEMAN, H. (Ed.). Society and the language classroom, Cambridge: Cambridge University Press, p. 169-203, 1996.

COTTERALL, S. Readiness for autonomy: Investigating learner beliefs. System, v. 23, n. 2, p.195-205, 1995.

DEWEY, J. How we think. Lexington: D. C. Heath. 1993.

ELLIS, R. The metaphorical constructions of second language learners. In: AAAL'98, 1998, Seatle. AAAL Anual Conference, Seatle: AAAL., 1998. 
ERLBAUM, B. E.; BERG, C. A.; DODD, D. H. Previous learning experiences, strategy beliefs, and task definition in self-regulated foreign Ianguage learning. Contemporary Educational Psychology, v. 18, n. 3, p. 318-336, 1993.

FREEMAN, D. The "unstudied problem": Research on teacher learning in language teaching. In: FREEMAN, D.; RICHARDS, J.C. (Ed.). Teacher leaming in language teaching, Cambridge: Cambridge University Press, 1996. p. 351-378.

GARCIA, C. R. P. As culturas de aprender uma língua estrangeira (inglês) em sala de aula que se propõe interdisciplinar. 1999. 125f. Dissertação (Mestrado em Lingüística Aplicada) - Instituto de Estudos da Linguagem, UNICAMP, Campinas.

GIMENEZ, T. Leamers becoming teacher: an exploratory study of beliefs held by prospective and practising EFL teachers in Brazil. 1994. 340f. Tese (Doutorado) Lancaster: Lancaster University.

GOODWIN, C.; DURANTI, A. Rethinking context: An introduction. In: DURANTI, A.; GOODWIN, C. (Ed.). Rethinking context: Language as an interactive phenomenon. Cambridge: Cambridge University Press, 1992. p. $1-42$.

HOLEC, $\mathrm{H}$. The learner as manager: managing learning or managing to learn? In: WENDEN, A.; RUBIN, J. (Ed.). Learner strategies in language learning. London: Prentice Hall, 1987. p. 145-156.

HOLLIDAY, A. Appropriate methodology and social context. Cambridge: Cambridge University Press, 1994.

HORWITZ, E. K. Using student beliefs about language learning and teaching in the foreign language methods course. Foreign Language Annals, v. 18, n. 4, p. 333-340, 1985.

HORWITZ, E. K. Surveying students' beliefs about language learning. In: WENDEN, A.; RUBIN, J. (Ed.). Learner strategies in language learning. London: Prentice Hall, 1987. p. 110-129.

HORWITZ, E. K. The beliefs about language learning of beginning university foreign language students. The Modem Language Joumal, v. 72, n. 3, p. 283-294, 1988.

KALAJA, P. Student beliefs (or metacognitive knowledge) about SLA reconsidered. International Journal of Applied Linguistics, v. 5, n. 2, p. 191-204, 1995.

KERN, R. G. Students' and teachers' beliefs about language learning. Foreign Language Annals, v. 28, n. 1, p. 71-92, 1995. 
KUNTZ, P. Students of 'easy' languages: Their beliefs about language learning. [ERIC Document Reproduction Service No. ED397658], 1996. KUNTZ, P. Students and their teachers of Arabic: Beliefs about language learning. ERIC Document Reproduction Service No. ED407854], 1997. MANTLE-BROMLEY, C. Positive attitudes and realistic beliefs: Links to proficiency. The Modern Language Journal, v. 79, n. 3, p. 372-386, 1995. LAVE, J. The practice of learning. In: CHAINKLIN, S.; LAVE. J. (Ed.). Understanding practice: Perspectives on activity and context. Cambridge: Cambridge University Press, 1993. p. 3-32

LOW, G. The semantics of questionnaire rating scales. Evaluation and Research in Education, v. 2, n. 2, p. 69-79, 1988.

LUPPESCU, S.; DAY, R. R. Examining attitude in teachers and students: the need to validate questionnaire data. Second Language Research, v. 6, n. 2, p. 125-134, 1990.

MCDONOUGH, J.; MCDONOUGH, S. H. Research methods for English language teachers. London: Arnold. 1997.

MUNBY, H. A qualitative approach to the study of a teacher's beliefs. Journal of Research in Science Teaching, v. 21, n. 1, p. 27-38, 1984.

MILLER, L. \& GINSBERG, R. B. Folklinguistic theories of language learning. In: FREED, B. F. (Ed.). Second language acquisition in a study abroad contextI. Amsterdam: John Benjamins, 1995. p. 293-315.

MORI, Y. Epistemological beliefs and language learning beliefs: What do language learners believe about their learning? [ERICDocument Reproduction Service No. ED406657], 1997.

MURPHEY, T. Experiencing and mapping in teacher education. In: SACHS, G.T., Brock, M.; Lo, R. (Ed.). Directions in second language teacher education. Hong Kong: City University of Hong Kong, 1996. p. 202-219. MURPHEY, T. Language hungry! An introduction to language learning fun and self-esteem. Tokyo: MacMillan. 1997.

NESPOR, J. The role of beliefs in the practice of teaching. Journal of Curriculum Studies, v. 19, n. 4, p. 317-328, 1987.

PAJARES, F. M. Teachers' beliefs and educational research: Cleaning up a messy construct. Review of Educational Research, v. 62, n. 3, p. 307-332, 1992.

PRESS, M-C. Ethnicity and the autonomous language learner: different beliefs and learning strategies? In: BROADY, E.; KENNING, M-M (Ed.). Promoting Learner autonomy in university language teaching. London: Association for French Studies/CILT, 1996. p.237-259. 
RAMANATHAN, V.; ATKINSON, D. Ethnographic approaches and methods in L2 writing research: A critical guide and Review. Applied Linguistics, v. 20, n. 1, 1999. p.44-70.

RICHARDS, J. C.; LOCKHART, C. Reflective teaching in second language classrooms. Cambridge: Cambridge University Press, 1994.

RICHARDSON, $\mathrm{V}$. The role of attitudes and beliefs in learning to teach. In: SIKULA, J. (Ed.). Handbook of Research on Teacher Education (2. ed.). New York: Macmillan,1996. p.102-119.

RILEY, P. The guru and the conjurer: aspects of counselling for selfaccess. In: BENSON, P. \& VOLLER, P. (Ed.). Autonomy and independence in language learning. New York: Longman, 1997. p.114131.

ROKEACH, M. Beliefs, attitudes, and values: A theory of organization and change. San Francisco: Jossey-Bass, 1968.

SCHWANDT, T. A. Qualitative Inquiry: a dictionary of terms. Thousand Oaks: Sage, 1997.

SAKUI, K.; GAIES, S. Investigating Japanese learners' beliefs about language learning. System, v. 27, n. 4, p. 473-492, 1999.

SU, D. A study of English learning strategies and styles of Chinese university students in relation to their cultural beliefs about learning English. 1995. Dissertação (Doutorado) - University of Georgia, Athens. SWALES, S.. From metaphor to meta-language. English Teaching Forum, v. 32, n. 3, p.8- 11, 1994.

TUMPOSKY, N. Student beliefs about language learning: A cross-cultural study. Carleton Papers in Applied Language Studies, v. 8, p. 50-65, 1991.

VALENZUELA, S. M. The management of language learning: Who is supposed to do what? Carleton Papers in Applied Language Studies, XIII, 1996. p. 21-35.

VIANA, N. A. A desconstrução dos mitos na aprendizagem de língua estrangeira. Uberlândia. Departamento de Letras, UFU, 1993. 5f. Mimeografado.

VICTORI, M. Investigating the metacognitive knowledge of students of English as a second language. 1992. Dissertação (Mestrado) - University of Califormia, Los Angeles.

VICTORI, M.; LOCKHART, W. Enhancing metacognition in self-directed language learning. System, v. 23, n. 2, p. 223-234, 1995. 
WEN, Q.; JOHNSON, R. K. L2 learner variables and English achievement. A study of tertiary-level English majors in China. Applied Linguistics, v. 18, p. 27-48, 1997.

WENDEN, A. Helping language learners think about learning. ELT Journal, v. 40, n.1, p.3-12, 1986.

WENDEN, A. How to be a successful language learner: insights and prescriptions from L2 learners. In: WENDEN, A. \& RUBIN, J. (Eds.). Learner strategies in language learning. London: Prentice Hall, 1987, p.103-117.

WENDEN, A. Learner strategies for learner autonomy. London: Prentice Hall. 1991.

WENDEN, A. Metacognitive knowledge and language learning. Applied Linguistics, v. 19, n. 4, p. 515-537, 1999.

WOODS, D. Teacher cognition in language teaching: Beliefs, decisionmaking, and classroom practice. Cambridge: Cambridge University Press. 1996.

WOODS, D. Decision-making in language learning: A lens for examining learner strategies. The Language Teacher Online, Outubro, 1997. [cited 26 May 1998]. Available from World Wide WeB: $\leq$ http:// langue.hyper.chubu.ac.jp/jalt/pub/t1t/97/oct/woods.html $\geq$ YANG, N.D. Second language learners' beliefs about language learning and their use of learning strategies: A study of college students of English in Taiwan. 1992. Tese (Doutorado) - The University of Texas, Austin. 